\title{
Management of commode injuries of Achilles tendon: a newly established tertiary care hospital-based study
}

\author{
Wajahat Ahmad Mir, Javaid Ahmad Ganaie, Rasiq Rashid*, Imran Khan, Ab Hai Qureshi
}

Department of Orthopedics, Government Medical College Anantnag, Jammu and Kashmir, India

Received: 11 November 2020

Revised: 15 December 2020

Accepted: 16 December 2020

\section{*Correspondence:}

Dr. Rasiq Rashid,

E-mail: drrasiq@gmail.com

Copyright: (c) the author(s), publisher and licensee Medip Academy. This is an open-access article distributed under the terms of the Creative Commons Attribution Non-Commercial License, which permits unrestricted non-commercial use, distribution, and reproduction in any medium, provided the original work is properly cited.

\begin{abstract}
Background: The Achilles tendon is the largest and strongest tendon in the body, formed by the union of gastrocnemius and soleus. Despite its strength, the Achilles tendon is vulnerable to injury, due to its subcutaneous position and the high tensions placed on it. Common mode of Achilles tendon injury nowadays in India is slipping of the foot in Indian type of commode and is often fraught with complications due to the potential contamination of wound at the time of injury. The purpose of this study was to assess the clinical outcome and complications of open Achilles tendon injury with an Indian type commode.

Methods: 30 patients who presented with open Achilles tendon injury between the ages of 10 to 55 years were included. All the patients were treated with emergency debridement, thorough washing and primary repair within 24 hours using Krackow technique.

Results: Out of the 30 patients meeting the inclusion criteria, there was 1 case of superficial infection which resolved with antibiotics and serial dressings. Foreign body sensation was present in 3 patients at final follow-up. Hypertrophic scar formation was seen in one patient. There were no cases of re-rupture in our study. Mean ROM at ankle in saggital plane at final follow-up was 66.13 degrees.

Conclusions: Commode injury is the most common cause of open Achilles tendon injury in Indian population. The complications can be minimized by early primary repair and should only be undertaken after thorough washing and debridement under proper antibiotic cover to contain the infection.
\end{abstract}

Keywords: Achilles tendon, Gastrocnemius, Soleus, Krackow technique, Saggital

\section{INTRODUCTION}

The Achilles tendon is the largest and strongest tendon in the body, formed by the union of gastrocnemius and soleus into one band of tissue that connects the calf muscles to the calcaneus. ${ }^{1}$ The tendon receives its blood supply from the musculotendinous junction, surrounding connective tissues, and the osteotendinous junction. The peroneal artery supplies the middle portion, while the posterior tibial artery supplies the proximal and distal portion. The relatively poor vascularisation of the mid-substance of the tendon might explain the poor healing potential of Achilles tendon injuries. ${ }^{2,3}$ When the calf muscles flex, the Achilles tendon pulls on the heel. This movement allows us to stand on our toes when walking, running, or jumping. Despite its strength, the Achilles tendon is also vulnerable to injury, due to the high tensions placed on it. ${ }^{4,5}$

Injury to Achilles tendon may occur due to sports injuries, accidental cuts by sharp household tools, penetrating injuries and road traffic accidents. Another common mechanism of Achilles tendon injury is India is slipping of 
the foot in Indian type of commode. The fall results in slipping of one foot into the hole of the commode thereby sustaining sharp cuts of skin and the Achilles tendon. ${ }^{6}$

The foot plate of the Indian type commode being in level with the surroundings as compared to its western counterpart, the chances of foot slipping into it are more. On slipping of foot into the hole of commode, the patient reflexively gets up by plantar flexing the foot. The taut Achilles tendon along with the overlying skin comes in contact with the overlying commode rim violently causing a partial or complete tear. ${ }^{7}$

The aim of this study was to assess the clinical outcome and complications of open Achilles tendon injury with an Indian type commode.

\section{METHODS}

This prospective interventional study was carried out in Govt. medical college Anantnag J and K India from June 2018 to May 2020 after obtaining clearance from institutional ethical committee. A total of 30 patients who had sustained an open tear of Achilles tendon with an Indian type of commode were included in the study.

\section{Inclusion criteria}

All sexes, open Tendo Achilles injury (commode injuries), age group of 10 to 55 years and injury less than 24 hours old.

\section{Exclusion criteria}

Closed injury, patients with co morbidities viz Diabetes, PVD, CKD, injury more than 24 hours old and associated fracture or vascular injury.

All the patients were admitted, stabilized and evaluated. Tetanus prophlaxis was given. Thorough washing of the wound with plenty of normal saline and povidone iodine was done in minor O.T. Wound was covered with sterile dressing pads soaked with povidone iodine solution and triple intravenous antibiotics which contained Cefuroxime, amikacin and metronidizole, were started within half an hour of presentation to the hospital.

\section{Operative procedure}

The surgical procedure was performed within 24 hours of the injury, either under regional or general anaesthesia as per the age and willingness of the patient. Patients were placed prone and laceration was extended into a $\mathrm{Z}$ shaped incision, debridement was done followed by thorough wash with normal saline and povidone iodine. With paratenon left intact, the two tendon ends were mobilized and approximated using Krackow suture technique using no. 2 to no. 5 ethibond suture. Wound was closed primarily in layers and above knee Plaster of Paris cast was applied, with knee in $15^{\circ}$ of flexion $\&$ the ankle in planter flexion.
Window was created in each cast on second post operative day for inspection of wound and change of dressings on alternate days. Intravenous antibiotics were continued for 5 days followed by oral antibiotics for further one week.

\section{Follow up}

The patients were kept non-weight bearing using crutches for first 4 weeks followed by gradual weight bearing. Follow-up was done at around 2, 4, 8, 12 and 24 weeks. The above knee casts were converted to below knee casts and brought to neutral position at 4 weeks and completely removed in all the patients at 8 weeks.

\section{Statistical analysis}

Data was entered in Microsoft excel software, and analysis was done using Statistical package for social sciences (SPSS) version 20.0 software.

\section{RESULTS}

Out of the 30 patients meeting the inclusion criteria, there were 18 males and 12 female patients and most of the patients (14) were in their twenties.

Table 1: Demographic data and functional outcome.

\begin{tabular}{|ll|}
\hline Demographic data & \\
\hline Mean age (years) & 29.67 \\
\hline Sex ratio (Males:Females) & $18: 12$ \\
\hline Side involved (Right:Left) & $13: 17$ \\
\hline Type of tear (Partial:Complete) & $7: 23$ \\
\hline $\begin{array}{l}\text { Mean ROM at ankle in saggital plane } \\
\text { (degrees) }\end{array}$ & 66.13 \\
\hline
\end{tabular}

Table 2: Complications.

\begin{tabular}{|lll|}
\hline Complication & $\begin{array}{l}\text { No. of } \\
\text { patients }\end{array}$ & Percentage \\
\hline $\begin{array}{l}\text { Foreign body } \\
\text { sensation }\end{array}$ & 3 & 10 \\
\hline Hypertrophic scar & 1 & 3.3 \\
\hline Superficial infection & 1 & 3.3 \\
\hline None & 25 & 83.3 \\
\hline
\end{tabular}

The mean age of the group was 29.67 (range: 10-55 years). The left side was affected in 17 patients $(56.7 \%)$ and right sided involvement was seen in 13 patients (43.3\%). 7 patients had partial tendon injury whereas 23 patients had complete tendon injury. There was 1 case of superficial infection which resolved with antibiotics and serial dressings. Mean ROM at ankle in saggital plane at final follow-up was 66.13 degrees (range: 54-72 degrees). Foreign body sensation was present in 3 patients at final follow-up. Hypertrophic scar formation was also seen in one patient. There were no cases of re-rupture in our study. 


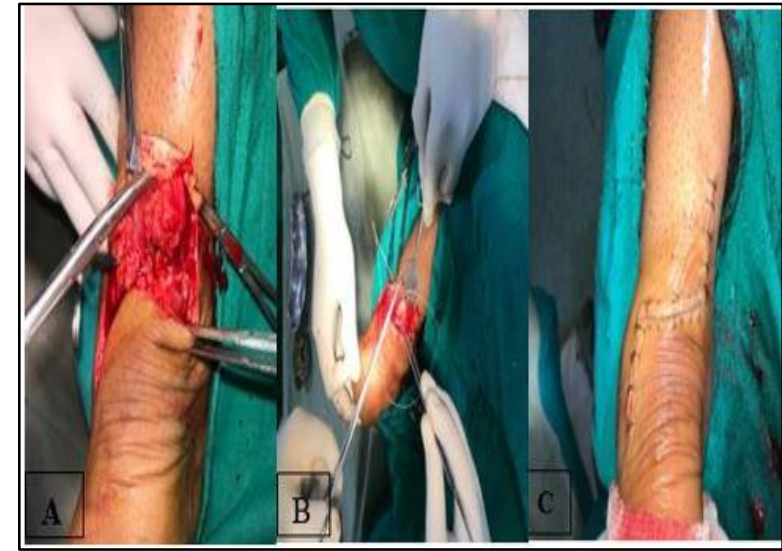

Figure 1: A) Wound extension, B) repair with ethibond using Krachow technique, C) skin closures with staples.

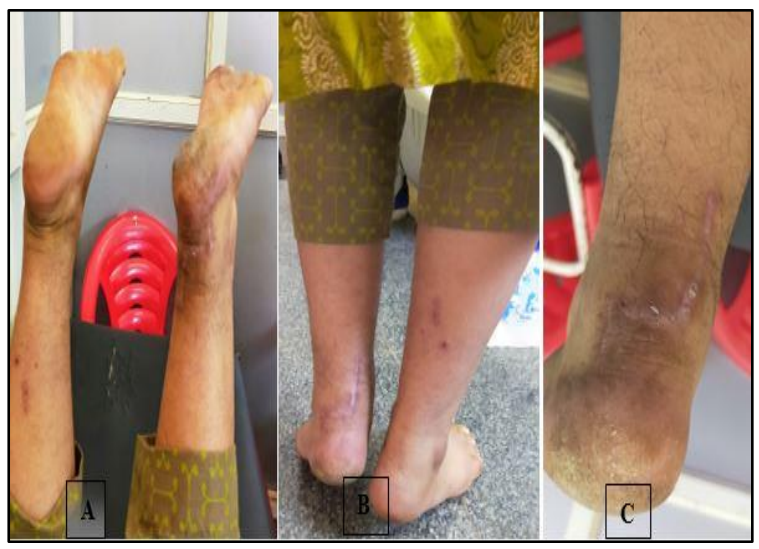

Figure 2: A) Normal plantar flexion, B) tip toe, C) post-operative scar.

\section{DISCUSSION}

Closed injuries of Achilles tendon are well described in literature. Sports activities have commonly been implicated for such injuries. ${ }^{8}$ Open tears of the Achilles tendon haven't been adequately reported in the literature. Out of that sparse literature available to us, Chatterjee et al. 6 in 2006 reported the commode injury as the common mode of injury in Indian scenario. Soring et al in 2019 reported 18 cases of open Achilles tendon tear and found that commode injury was most common cause. ${ }^{9}$ The mechanism of injury has been found similar as has been described by Dar et al. ${ }^{7}$ More over the damage in the commode brim seems to be the additional factor contributing to the injury. The complications viz; rerupture, granuloma formation, discharging sinuses, skin edge necrosis, deep infections have been mentioned in literature but we did not encounter such complications in our study. ${ }^{6,10,11}$ The reason could be thorough initial debridement and washing under adequate antibiotic cover, followed by early primary repair using ethibond. We saw superficial infection in 1 case, hypertrophic scar in 1 case and foreign body sensations in three cases. The reason for foreign body sensation could be sural nerve irritation with suture material. Ankle ROM at final follow-up was comparable with other studies in literature. ${ }^{6,12}$

\section{CONCLUSION}

Commode injury is the most common cause of open Achilles tendon injury in Indian population and seems to be non preventable. The complications can be minimized by early primary repair and delayed weight bearing. But the repair of tendon should only be undertaken after thorough washing and debridement under proper antibiotic cover to contain the infection.

\section{Funding: No funding sources \\ Conflict of interest: None declared}

Ethical approval: The study was approved by the institutional ethics committee

\section{REFERENCES}

1. Doral MN, Alam M, Bozkurt M. Functional anatomy of the Achilles tendon. Knee Surg Sports Traumatol Arthrosc. 2010;18:638-643.

2. Benjamin M, McGonagle D. The anatomical basis for disease localisation in seronegative spondyloarthropathy at enthe-ses and related sites. J Anat. 2001;199:503-26.

3. Chen TM, Rozen WM, Pan WR, Ashton MW, Richardson MD, Taylor GI. The arterial anatomy of the Achilles tendon: anatomical study and clinical implications. Clin Anat. 2009;22:377-85.

4. Fugl-Meyer AR, Nordin G, Sjostrom M, Wahlby L. Achilles tendon injury. A model of isokinetic strength training using bio feedback. Scand J Rehabil Med.1979;11:37-44.

5. Grumbine NA, Santoro JP. The tendo Achillis as it relates to rear foot position. A new classification for evaluation of calcaneal stance position. Clin Podiatr Med Surg. 1990;7:203-16.

6. Chatterjee SS, Sarkar A, Misra A. Management of acute open tendo-achilles injuries in Indian lavatory pans. Indian J Plast Surg. 2006;39(1):29-30.

7. Dar TA, Sultan A, Dhar SA, Ali MF, Wani MI, Wani SA. Toilet seat injury of the Achilles tendon a series of twelve cases. Foot and Ankle Surgery. 2011;17(4):284-86.

8. Theobald P, Benjamin M, Nokes L. Review of the vascularisation of the human Achilles tendon. Injury, Int.J. Care Injured. 2005;36:1267-1272.

9. Soring D, Singh AM, Chishti SN, Nag R,Tada K, Sharma KK. Clinical outcome of open Achilles tendon injuries within12 hours of primary repair. IOSR Journal of Dental and Medical Sciences. 2019;18(1):16-20.

10. Wills CA, Washburn S, Caiozzo V, Preitto CA. Achilles tendon rupture. A review of the literature comparing surgical versus non surgical treatment. Clin Orthopaed Relat Res. 1986;207:156-63.

11. Paavola M, Orava S, Leppilathi J, Kannus P, Jarvinen M. Chronic Achilles tendon overuse injury: 
Complications after surgical treatment: An analysis of 432 consecutive patients. Am J Sports Med. 2000;28:77-82.

12. Porter DA, Mannarino FP, Snead D, Gabel SJ, Ostrowski M. Primary repair without augmentation for early neglected Achilles tendon ruptures in the recreational athlete. Foot Ankle Int. 1997;18:557-64.
Cite this article as: Mir WA, Ganaie JA, Rashid R, Khan I, Qureshi AH. Management of commode injuries of Achilles tendon: a newly established tertiary care hospital-based study. Int J Res Orthop 2021;7:116-9. 